\title{
Nitidine chloride induces apoptosis in human hepatocellular carcinoma cells through a pathway involving p53, p21, Bax and Bcl-2
}

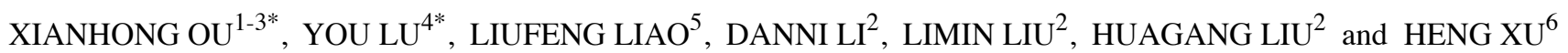 \\ ${ }^{1}$ College of Pharmacy, Guilin Medical University, Guilin 541004; ${ }^{2}$ College of Pharmacy, Guangxi Medical University, \\ Nanning 530021, Guangxi Zhuang Autonomous Region; ${ }^{3}$ Department of Electrophysiology, Institute of \\ Cardiovascular Research, Luzhou Medical College, Luzhou 646000, Sichuan; ${ }^{4}$ Guangxi University of \\ Chinese Medicine; ${ }^{5}$ Affiliated Tumor Hospital of Guangxi Medical University; \\ ${ }^{6}$ Experimental Center of Medical Sciences, Guangxi Medical University, \\ Nanning 530021, Guangxi Zhuang Autonomous Region, P.R. China
}

Received July 4, 2014; Accepted October 7, 2014

DOI: $10.3892 /$ or.2014.3688

\begin{abstract}
Nitidine chloride (NC), a novel benzo[c]phenanthridine alkaloid, induces the growth inhibition of cancer cells. Previously it was demonstrated that SMMC-7721 human hepatocellular carcinoma (HCC) cells are highly susceptible to the antiproliferative effects of NC. However, the specific mechanisms remained unclear. In the present study the pathways of growth inhibition induced by $\mathrm{NC}$ in SMMC-7721 cells were investigated. The effects of NC on SMMC-7721 cell proliferation were characterized by MTT and colony formation assays. Additionally, BALB/c nude mice were transplanted with SMMC-7721 cells to verify the inhibition of HCC by NC in vivo. The results showed that NC inhibited the proliferation of SMMC-7721 cells in vitro in a time- and dose-dependent manner and identified efficacy in vivo in a mouse model of HCC. Acridine orange (AO) staining, transmission electron microscopy, Annexin V/PI staining, TUNEL assay and caspase-3 activation assays were used to investigate apoptosis and the cell cycle distribution. Inhibition was mediated in part by cell cycle arrest in $G_{2} / M$, leading to chromatin condensation, DNA fragmentation and
\end{abstract}

Correspondence to: Professor Hua-Gang Liu, College of Pharmacy, Guangxi Medical University, No. 22 Shuangyong Road, Nanning 530021, Guangxi Zhuang Autonomous Region, P.R. China E-mail: hgliu2013@163.com

Professor Heng Xu, Experimental Center of Medical Sciences, Guangxi Medical University, No. 22 Shuangyong Road Nanning 530021, Guangxi Zhuang Autonomous Region, P.R. China E-mail: dnareplication@163.com

*Contributed equally

Key words: nitidine chloride, SMMC-7721, apoptosis, cell cycle arrest, p53 the formation of apoptotic bodies. Apoptosis was also verified by Annexin V/PI staining, TUNEL assay and caspase-3 activation. To assess the levels of the cell cycle and apoptotic regulators, immunohistochemical staining, ELISA, real-time PCR and RNA interference (RNAi) were employed. The apoptotic process triggered by $\mathrm{NC}$ involved the upregulation of p53, p21 and Bax, and the downregulation of Bcl-2. These data elucidate a pathway of apoptosis in SMMC-7721 cells that involves $\mathrm{G}_{2} / \mathrm{M}$ arrest, upregulation of $\mathrm{p53}$, Bax, caspase-3 and $\mathrm{p} 21$, and downregulation of $\mathrm{Bcl}-2$.

\section{Introduction}

Hepatocellular carcinoma (HCC) has an annual worldwide incidence of 626,000 cases and causes 550,000 deaths per year (1), 55\% of which are in China (2). Although surgical resection is the mainstay of therapeutic strategy, chemotherapy is a last resort for inoperable or metastatic disease. However, the chemotherapeutic agents that are effective for $\mathrm{HCC}$ have significant tissue toxicity. Thus, therapeutic strategies that target tumor cells without compromising normal tissue function are required (3). Herbal medicines have become increasingly popular in China and throughout the world. There are at least 120 species of poisonous botanicals, animals and minerals, of which more than half have been found to possess significant anticancer properties (4). Due to the wide range of biological activities and low toxicity in animal models, natural products have been assessed as alternative treatments for various types of cancer, including liver cancer. However, some normal cells are always destroyed in the process of killing tumor cells, even for alternative treatments. Therefore, it is essential to identify additional novel natural compounds with low toxicity and high selectivity for killing liver cancer cells.

The traditional Chinese medicinal plant Zanthoxylum nitidum (Roxb.) DC from southern China contains $>30$ benzo[c]phenanthridinium alkaloids (5-7), including nitidine, oxynitidine, oxychelerythrine, dihydronitidine and nitidine chloride (NC) (8). The NC compound, which is more 
abundant than other alkaloids, constitutes $1.49 \times 10^{-3}(\mathrm{~g} / \mathrm{g})$ of the Zanthoxylum nitidum (Roxb.) DC root (7). The molecular formula of $\mathrm{NC}$ is $\mathrm{C}_{21} \mathrm{H}_{18} \mathrm{O}_{4} \mathrm{NC} \cdot 2 \mathrm{H}_{2} \mathrm{O}$ and its chemical structure is provided in Fig. 1A (7).

$\mathrm{NC}$ is highly cytotoxic and has proven activity in L1210 and P388 leukemias (9,10), Lewis lung carcinoma (9), lung adenocarcinoma (11), Ehrlich ascites carcinoma (12), B16 melanocarcinoma (10), breast cancer (13), osteosarcoma (14), gastric (15) and renal cancer (16). Benzo[c]phenanthridine derivatives, including NC, have shown selective cytotoxicity as an anticancer agent in vivo $(11,17)$, suggesting that $\mathrm{NC}$ has the potential to be an effective new drug for cancer suppression. NC induces apoptosis in the 7111 and Ecv2 nasopharyngeal carcinoma cell lines and in the KB oral carcinoma cell line $(18,19)$, with a higher chemotherapeutic index in liver than in the kidney (20). However, the mechanisms of action of $\mathrm{NC}$ against human $\mathrm{HCC}$ are largely unknown. In the present study, we investigated the effects of $\mathrm{NC}$ on the proliferation of human liver cancer cells and its mechanisms of action. The results obtained provide a pathway of p53-dependent apoptosis by NC in HCC.

\section{Materials and methods}

Cell culture. The human SMMC-7721 HCC cell line was obtained from the Shanghai Institute of Materia Medica, Chinese Academy of Sciences (Shanghai, China). Cells were cultured in RPMI-1640 medium, supplemented with $10 \%$ fetal bovine serum (Gibco Life Technologies, Carlsbad, CA, USA) in a humidified atmosphere of $5 \% \mathrm{CO}_{2}$ at $37^{\circ} \mathrm{C}$.

Drug preparation. NC (98\% purity) was purchased from the National Institute of Food and Drug Control (Beijing, China). $\mathrm{NC}$ was prepared as a $10 \mathrm{mM}$ stock solution in dimethyl sulfoxide (DMSO) and stored in aliquots at $4{ }^{\circ} \mathrm{C}$ prior to use. Cytoxan [cyclophosphamide, (CTX)] was obtained from the Jiangsu Hengrui Medicine Co., Ltd. (China). CTX was prepared in $0.9 \%$ sterile sodium chloride solution at a concentration of $20 \mathrm{mg} / \mathrm{ml}$.

MTT cell proliferation assay. The antiproliferative effect of NC on SMMC-7721 cells was evaluated by determining the $\mathrm{IC}_{50}$ value, which is defined as the concentration required for $50 \%$ inhibition of cell growth. Logarithmically growing cells were seeded at a density of $1-5 \times 10^{4}$ cells/well in 96-well plates (Corning Inc., Corning, NY, USA) and allowed to adhere for $12 \mathrm{~h}$ at $37^{\circ} \mathrm{C}$. The medium was then replaced with fresh medium containing various concentrations of NC. The cells were maintained for 2 days, and the antiproliferative activity of NC was determined using MTT (Amresco, Solon, OH, USA). MTT $(10 \mu \mathrm{l})(5 \mathrm{mg} / \mathrm{ml}$ stock) was added to each well for $4 \mathrm{~h}$, the seeding medium was discarded and $0.15 \mathrm{ml}$ DMSO was added to each well. Absorbance was read at $570 \mathrm{~nm}$. The cell inhibition ratio was determined as: $\left(1-\mathrm{A}_{\text {treated group }} / \mathrm{A}_{\text {control group }}\right) \mathrm{x} 100$.

Morphological examination by phase contrast microscopy. For the morphological examination, the cells were cultured in 24-well plates. After 24-h treatment with NC, the cells were observed and photographed using a Leica DMI3000B inverted microscope (Leica, Wetzlar, Germany).
Colony formation assay. Cells were counted, plated in triplicate at $1 \times 10^{3}$ cells/well in 6 -well plates and allowed to adhere for $12 \mathrm{~h}$. The cells were then cultured in culture medium containing various concentrations of $\mathrm{NC}$ for 10 days. After most of the colonies expanded to $\sim 50$ cells, they were washed twice with phosphate-buffered saline (PBS) and fixed in methanol for $15 \mathrm{~min}$. The plates were photographed, and colonies $>50$ cells were counted using Quantity One 4.6.2 (Bio-Rad, Hercules, CA, USA). At least three independent experiments were carried out for each assay.

Transmission electron microscopy (TEM). After exposure to $\mathrm{NC}$, the cells were fixed in ice-cold $2.5 \%$ glutaraldahyde and preserved at $4{ }^{\circ} \mathrm{C}$ for further processing. The cells were then post fixed in $1 \%$ osmium tetroxide in $2.5 \%$ glutaraldahyde, dehydrated in graded alcohol, embedded in Epon 812, sectioned with an ultramicrotome, and stained with uranyl acetate and lead citrate. The sections were examined with a transmission electron microscope (JEM-1200EX, JEOL Ltd., Tokyo, Japan).

Acridine orange staining. Apoptotic nuclear morphology was assessed by acridine orange (AO) staining (Sigma, St. Louis, MO, USA). Cells treated with $0,0.5$ or $1.0 \mu \mathrm{g} / \mathrm{ml} \mathrm{NC}$ for $48 \mathrm{~h}$ were collected, washed with PBS and then fixed with $95 \%$ ethanol for $15 \mathrm{~min}$. After being acidified with $1 \%$ acetic acid for $30 \mathrm{sec}$, the coverslips were dyed with $0.1 \mathrm{~g} / 1 \mathrm{AO}$ for $10 \mathrm{~min}$. The slips were differentiated with $0.1 \mathrm{~mol} / 1 \mathrm{CaCl}_{2}$ for $2 \mathrm{~min}$, washed with PBS three times, and the nuclear morphology was examined under a fluorescent microscope (Leica).

Flow cytometry. The percentage of cells undergoing apoptotic cell death induced by $\mathrm{NC}$ was measured by flow cytometry using the Annexin V-FITC/PI kit (Nanjing KeyGen Biotech Co., Ltd., China) according to the manufacturer's instructions. Cells treated with NC for $24 \mathrm{~h}$ were collected and washed twice with PBS. The cells were resuspended in $500 \mu \mathrm{l}$ binding buffer, and then $5 \mu \mathrm{l}$ of Annexin V-FITC and $5 \mu \mathrm{l}$ of propidium iodide (PI) were added into the cell suspension, followed by gentle vortexing. The stained samples were incubated for $15 \mathrm{~min}$ at room temperature in the dark and then analyzed using a Beckman Coulter FACSCalibur-500 flow cytometer within $1 \mathrm{~h}$. Events $(100,000)$ were obtained using the green channel FL1 for Annexin V-FITC and the red channel FL3 for PI.

Measurement of caspase-3 activity. The Caspase-3 Activity Assay kit (Beyotime Institute of Biotechnology, Jiangsu, China) was used for the detection of caspase-3 activity according to the manufacturer's instructions. Briefly, control and treated cells were collected, washed with ice-cold PBS, and resuspended in $50 \mu \mathrm{l}$ of chilled cell lysis buffer for $15 \mathrm{~min}$ on ice. Lysates were clarified by centrifugation $(20,000 \mathrm{x} \mathrm{g}$, $10 \mathrm{~min}, 4^{\circ} \mathrm{C}$ ) and assayed immediately.

Immunohistochemical staining for Bax and Bcl-2. Cells were cultured to the logarithmic growth phase, and the cell numbers were adjusted to $1 \times 10^{4} / \mathrm{ml}$ after trypsinization. Six-well plates were seeded with $1 \times 10^{4}$ cells/well and cultured for $12 \mathrm{~h}$. After treatment with $\mathrm{NC}(2.0 \mu \mathrm{g} / \mathrm{ml})$ for $24 \mathrm{~h}$, immunohis- 
Table I. PCR primer sequences.

\begin{tabular}{|c|c|c|c|}
\hline Gene & Sequence & $\begin{array}{l}\mathrm{Tm} \\
\left({ }^{\circ} \mathrm{C}\right)\end{array}$ & $\begin{array}{l}\text { Product } \\
\text { (bp) }\end{array}$ \\
\hline \multirow[t]{2}{*}{$\beta$-actin } & FP: 5'-AAGAAGGTGGTGAAGCAGGC-3' & & \\
\hline & RP: 5'-TCCACCACCCTGTTGCTGTA-3' & 60 & 203 \\
\hline \multirow[t]{2}{*}{$p 53$} & FP: 5'-GGCCCACTTCACCGTACTAA-3' & & \\
\hline & RP: 5'-GTGGTTTCAAGGCCAGATGT-3' & 60 & 186 \\
\hline \multirow[t]{2}{*}{$p 21$} & FP: 5'-CGACTGTGATGCGCTAATGG-3' & & \\
\hline & RP: 5'-CGTGGGAAGGTAGAGCTTGG-3' & 60 & 145 \\
\hline
\end{tabular}

tochemical staining was performed to detect Bax and $\mathrm{Bcl}-2$ protein. Briefly, the activity of endogenous peroxidase in the samples was quenched by incubation in 3\% hydrogen peroxide solution for $10 \mathrm{~min}$. The coverslips were then incubated with antibody against Bax and Bcl-2 (Zhongshan Golden Bridge Biotechnology Co., Ltd., Beijing, China) at $4^{\circ} \mathrm{C}$ overnight. The staining was completed by incubation with substratechromogen 3,3'-diaminobenzidine (DAB; Zhongshan Golden Bridge Biotechnology Co., Ltd). The coverslips were then stained, dehydrated and mounted. Negative control slides were prepared by replacing the primary antibody with PBS. Five different zones of each slide were selected at random for microscopic visualization, and the positive cell numbers and average optical density $\left(\mathrm{A}_{\mathrm{OD}}\right)$, defined as the ratio of the positive target optical density and the positive area percentage $\left(\mathrm{I}_{\mathrm{OD}} /\right.$ Area), were analyzed using a pathological image analysis system (Leica DMR + Q550).

Enzyme-linked immunosorbent assay (ELISA). After exposure of SMMC-7721 cells to NC, the concentrations of p53 and p21 in cell supernatants were determined using the human p53 and human p21 ELISA kits (Shanghai XINUO Biotechnology Co., Ltd., Shanghai, China), according to the manufacturer's instructions. Optical density was read using a microplate reader (Bio-Rad) at $450 \mathrm{~nm}$. A standard curve was generated by correlating the original concentrations of the targeted factor and the corresponding optical densities. The concentrations of p53 and p21 in samples were calculated according to the standard curve.

Quantitative PCR. Primers for quantitative PCR (qPCR) were designed and synthesized by Sangon (Shanghai, China) (Table I). Total RNA was isolated from cells using TRIzol reagent (Invitrogen Life Technologies, Carlsbad, CA, USA). cDNA was synthesized from the isolated RNA using the RevertAid $^{\mathrm{TM}}$ First Strand cDNA Synthesis kit (Tiangen Biotech Co., Ltd., Beijing, China). Reverse transcription was performed using oligo(dT) primers at $25^{\circ} \mathrm{C}$ for $10 \mathrm{~min}, 42^{\circ} \mathrm{C}$ for $60 \mathrm{~min}$, and then $70^{\circ} \mathrm{C}$ for $10 \mathrm{~min}$. qPCR was performed using a SYBR-Green qPCR kit [Tiangen Biotech (Beijing) Co., Ltd.] according to the manufacturer's instructions in an iCycler iQ 7500 real-time PCR system (Bio-Rad) for 35 cycles. A gene expression normalization factor was calculated for each sample based on the geometric mean of $\beta$-actin as a user-defined housekeeping gene.
Animals. Four- to 6-week female BALB/c nude mice (weighing 18-20 g) were provided by the Experimental Animal Center of Guangxi Medical University (Nanning, China). The mice were bred and maintained at our institute under specific pathogen-free conditions, with continuous free access to sterilized food and autoclaved water under a controlled $12 \mathrm{~h} \mathrm{light/dark}$ cycle at $22-25^{\circ} \mathrm{C}$ with $50 \%$ relative humidity. All the animal procedures were approved by the Animal Ethics Committee of Guangxi Medical University.

Immunodeficient $\mathrm{BALB} / \mathrm{c}$ nude mice were randomized and then subcutaneously implanted with $0.2 \mathrm{ml}$ SMMC-7721 cells at a density of $1 \times 10^{7}$ cells $/ \mathrm{ml}$ into the right axilla. Nude mice bearing tumors of $150-300 \mathrm{~mm}^{3}$ were selected for experimentation. Mice bearing human SMMC-7721 HCCs were randomized into the $\mathrm{NC}$ group $(10 \mathrm{mg} / \mathrm{kg} \mathrm{NC} /$ day $)$, the CTX group $(20 \mathrm{mg} / \mathrm{kg}$ cytoxan/day) and the control normal saline group (0.2 $\mathrm{ml}$ saline/day). Drug administration (i.p. injection once per day for 14 days) was commenced on the day after tumor implantation. The tumor dimensions were measured at 7-day intervals using a caliper for length and width. Tumor size was then calculated as described previously (21) using the equation:

$$
\text { Tumor size }\left(\mathrm{mm}^{3}\right)=\left\{[(\mathrm{W}+\mathrm{L}) / 2]^{3}\right\} \times 2
$$

where $\mathrm{W}$ is the width and $\mathrm{L}$ is the length. After 14 days of treatment, the animals were euthanized and the tumors were collected.

TUNEL assay. Apoptosis in tumor tissue sections was determined using the In Situ Cell Death Detection kit (Roche, Bromma, Sweden). Briefly, tumor tissue sections of formalinfixed, paraffin-embedded specimens were dewaxed in xylene and rehydrated in a graded series of ethanol. The tumor samples were incubated with proteinase $\mathrm{K}(2 \mathrm{mg} / \mathrm{ml})$, and TUNEL staining was performed according to the manufacturer's instructions.

RNA interference. Endogenous levels of p53 were depleted by RNA interference-mediated suppression using the following double-stranded RNA oligonucleotides: forward, 5'-CUA CUUCCUGAAAACAACGTT-3' and reverse, 5'-CGUUGU UUUCAGGAAGUAGTT-3 for human p53 mRNA (GenBank accession no. AB082923.1). Short hairpin interfering RNA (shRNA) molecules that target the same sequences of human 
A

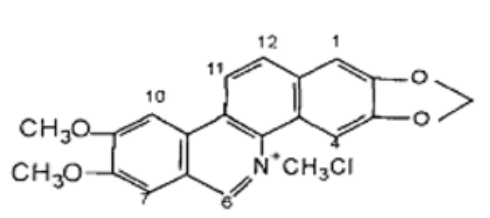

B

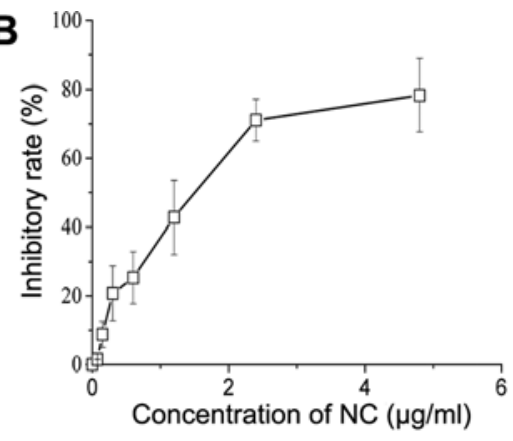

D

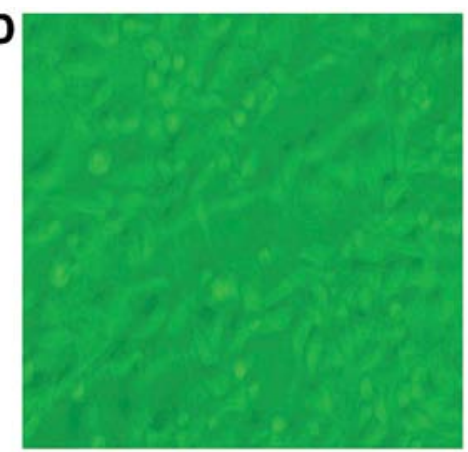

Control

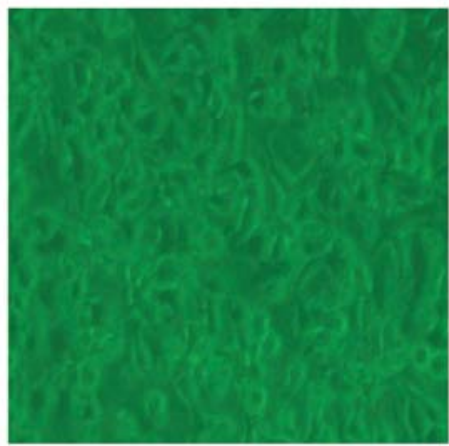

$1.0 \mu \mathrm{g} / \mathrm{ml} \mathrm{NC}$
$0.5 \mu \mathrm{g} / \mathrm{ml} \mathrm{NC}$

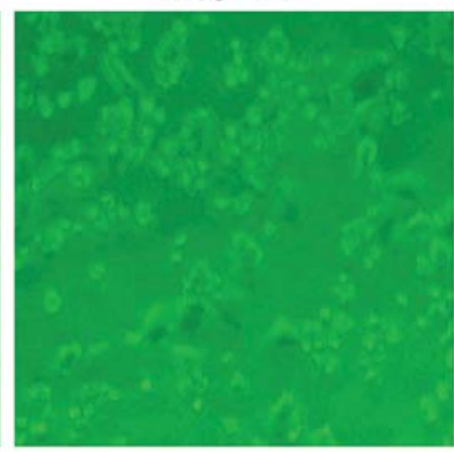

$2.0 \mu \mathrm{g} / \mathrm{ml} \mathrm{NC}$

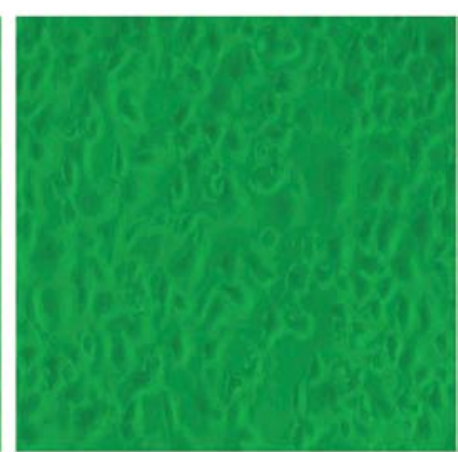

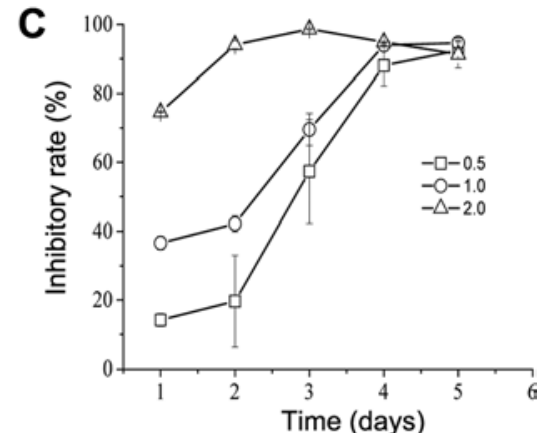

E

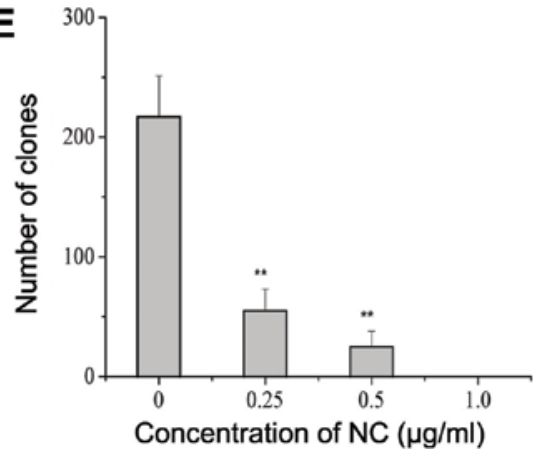

Figure 1. Nitidine chloride (NC) inhibits SMMC-7721 cell growth in vitro. (A) The chemical structure of NC is provided. NC was isolated from the traditional Chinese medicine plant, Zanthoxylum nitidum (Roxb.) DC. (B and C) SMMC-7221 cell proliferation was assayed by MTT assay following treatment with $0.075,0.15,0.3,0.6,1.2,2.4$ or $4.8 \mu \mathrm{g} / \mathrm{ml} \mathrm{NC}$ for one day (B); or following treatment with $0.5,1.0 \mathrm{or} 2.0 \mu \mathrm{g} / \mathrm{ml} \mathrm{NC}$ for 1,2,3,4 or $5 \mathrm{days}(\mathrm{C})$. Data are presented as means \pm SD $(n=3)$. (B) The $\mathrm{IC}_{50}$ value was calculated using a dose-response curve to assess the efficiency of growth inhibition. (D) The morphological changes in SMMC-7721 cells were examined by phase contrast microscopy (control) with or without $48 \mathrm{~h}$ exposure to $0.5,1.0$ or $2.0 \mu \mathrm{g} / \mathrm{ml}$ of $\mathrm{NC}$, respectively (x100). (E) The average number of colones/field was calculated, ${ }^{*} \mathrm{P}<0.05 ;{ }^{* *} \mathrm{P}<0.01$ compared with the control group (untreated). Results are representative of at least three independent experiments.

p53 were cloned into the eukaryotic expression vector pGPU6/GFP/neo, which was purchased from GeneChem (Shanghai, China). Additionally, a pGPU6/GFP/neo plasmid carrying an shRNA targeting luciferase (target sequence: forward, 5'-UUCUCCGAACGUGUCACGUTT-3' and reverse, 5'-ACGUGACACGUUCGGAGAATT-3') was used as a negative control.

Transfection of HCC cells with p53 shRNA-expression vector. SMMC-7721 cells (1x10\%/well) were plated in 6-well plates in RPMI-1640 medium supplemented with 10\% FBS. After $24 \mathrm{~h}$, $1.5 \mu \mathrm{g}$ of DNA was transfected using Lipofectamine 2000 (Invitrogen Life Technologies) according to the manufacturer's instructions. After 24-h transfection, the cells were treated with $1.0 \mu \mathrm{g} / \mathrm{ml} \mathrm{NC}$ for an additional 24 or $48 \mathrm{~h}$ for MTT assay, AO staining and ELISA analysis. Transfected cells were as designated 7721-pGPU6/GFP-C control shRNA (con shRNA, control), 7721-pGPU6/GFP-p53shRNA (p53 ${ }^{-/}$).

Data analysis. Data were presented as means \pm standard deviation (SD) in triplicate and analyzed using SPSS software (version 15.0; SPSS, Inc., Chicago, IL, USA). The difference among various groups was analyzed by ANOVA, and $\mathrm{P}<0.05$ was considered to indicate a statistically significant result.

\section{Results}

NC inhibits HCC cell proliferation. To verify the effects of NC on inhibiting $\mathrm{HCC}$ cell proliferation and to determine an effective concentration of NC, we performed MTT assays following treatment of SMMC-7721 cells at a range of doses. NC caused a dose-dependent decrease in SMMC-7221 cell growth, 
Table II. Effects of NC on human HCC SMMC-7721 tumors transplanted in nude mice (mean \pm SD, $\mathrm{n}=5$ ).

\begin{tabular}{lccccc}
\hline & & \multicolumn{3}{c}{ Weight $(\mathrm{g})$} & \\
\cline { 3 - 4 } Groups & $\begin{array}{c}\text { Dose } \\
(\mathrm{mg} / \mathrm{kg})\end{array}$ & Begin & End & Tumor \\
weight $(\mathrm{g})$ & IR $(\%)$ \\
\hline NS & - & $19.43 \pm 1.71$ & $23.01 \pm 1.28$ & $1.78 \pm 0.44$ & - \\
CTX & 20 & $21.12 \pm 2.21$ & $22.03 \pm 2.45$ & $1.17 \pm 0.30^{\mathrm{a}}$ & 34.27 \\
NC & 10 & $20.13 \pm 2.42$ & $21.98 \pm 2.54$ & $1.23 \pm 0.27^{\text {a }}$ & 30.90 \\
\hline
\end{tabular}

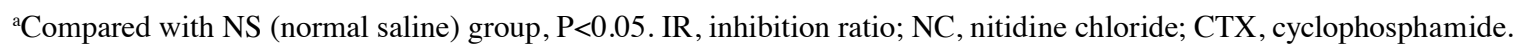
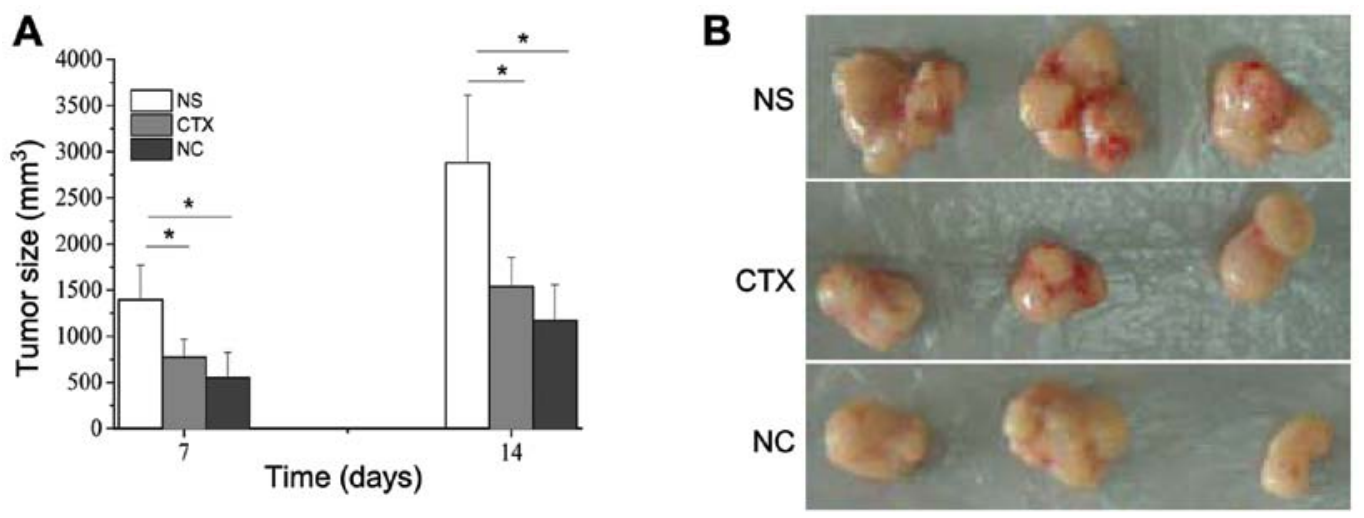

Figure 2. Nitidine chloride (NC) effectively inhibits SMMC-7221 cell growth in a mouse model. (A) Tumor growth was measured 7 or 14 days following injection of mice with saline as negative control (NS), with the therapeutic drug, cyclophosphamide (CTX) or with $10 \mu \mathrm{g} / \mathrm{ml} \mathrm{NC}$. Results are presented as means $\pm \mathrm{SD}$ ( $\mathrm{n}=5$ mice per group). (B) Three representative excised tumors from each of the groups in (A) are shown after treatment for 14 days.

with an $\mathrm{IC}_{50}$ values of $1.08 \mu \mathrm{g} / \mathrm{ml}$ (Fig. 1B). For practical purposes, NC concentrations that cause a $25 \%$ reduction in cell viability with no apparent pro-apoptotic effect after 24-h treatment $(0.5 \mu \mathrm{g} / \mathrm{ml}$ for SMMC-7221 cells) are considered to be non-cytotoxic and have been used to study the effects on cell cycle progression (22), while the $\mathrm{IC}_{50}$ values at $24 \mathrm{~h}$ are regarded as cytotoxic. To examine the effects of $\mathrm{NC}$ at a range of doses, we included doses of $0.5,1.0$ and $2.0 \mu \mathrm{g} / \mathrm{ml}$ in subsequent in vitro studies. The NC inhibition of SMMC-7221 cells at these three concentrations was time-dependent, as shown by treatment for 1, 2, 3, 4 and 5 days (Fig. 1C).

To further examine the morphological changes following $\mathrm{NC}$ treatment at doses that span the $\mathrm{IC}_{50}$ values, we treated SMMC-7221 cells with $0.5,1.0$ and $2.0 \mu \mathrm{g} / \mathrm{ml}$ of $\mathrm{NC}$ for $48 \mathrm{~h}$, and assessed the morphology using light microscopy. SMMC-7721 cells in the control group exhibited a normal and healthy shape, demonstrated by clear cytoskeletons. By contrast, NC-treated cells exhibited cell shrinkage, which was obvious for the $2.0 \mu \mathrm{g} / \mathrm{ml} \mathrm{NC}$ group (Fig. 1D). The number of SMMC-7721 colones was also strongly reduced following $\mathrm{NC}$ treatment (Fig. 1E). These findings verify that $\mathrm{NC}$ affects the morphology and growth of SMMC-7221 cells, and that its cytotoxic effect is dose- and time-dependent.

NC inhibits the growth of human HCC SMMC-7721 tumors transplanted in nude mice. To determine whether NC effectively inhibits HCC tumor growth in vivo, SMMC-7221 cells were transplanted into nude mice and $10 \mathrm{mg} / \mathrm{kg} / \mathrm{day} \mathrm{NC}$ was injected. As a control chemotherapeutic, the nitrogen mustard alkylating agent, CTX was injected into a separate group of mice. After 7 or 14 days treatment, transplanted SMMC7721 tumors were significantly smaller than the untreated or CTX-treated tumors (Fig. 2A). The inhibition ratio was $30.90 \%$, suggesting a significant difference from the control $(\mathrm{P}<0.05$; Table II). Furthermore, the volume of tumor tissue in the NC group was less than that of the control $(\mathrm{P}<0.05$; Fig. 2B). These results suggested that NC is efficacious in the treatment of HCC in an in vivo model.

$N C$ arrests the cell cycle at the $G_{2} / M$ phase. A variety of agents trigger growth inhibition as well as cell death (23). Cell cycle arrest commonly leads to growth inhibition and is therefore a good marker for chemopreventive or antitumor activity (24). However, no reports have determined a checkpoint for the cell cycle arrest of SMMC-7721 cells by NC. To determine the effects of NC on SMMC-7221 cell cycle distribution, we performed flow cytometry. Untreated cells (controls) showed the expected pattern of continuously growing cells, in which a high peak was observed in the $G_{1}$ phase region and a lower peak in the $\mathrm{G}_{2} / \mathrm{M}$ phase. However, following treatment with $0.5,1.0$ or $2.0 \mu \mathrm{g} / \mathrm{ml} \mathrm{NC}$, the $\mathrm{G}_{1}$ percentage progressively decreased while the $\mathrm{G}_{2} / \mathrm{M}$ percentage increased, with a statistical increase in the $\mathrm{G}_{2} / \mathrm{M}$ phase distribution after 1.0 and $2.0 \mu \mathrm{g} / \mathrm{ml}$ of NC (Table III). This finding suggests that 

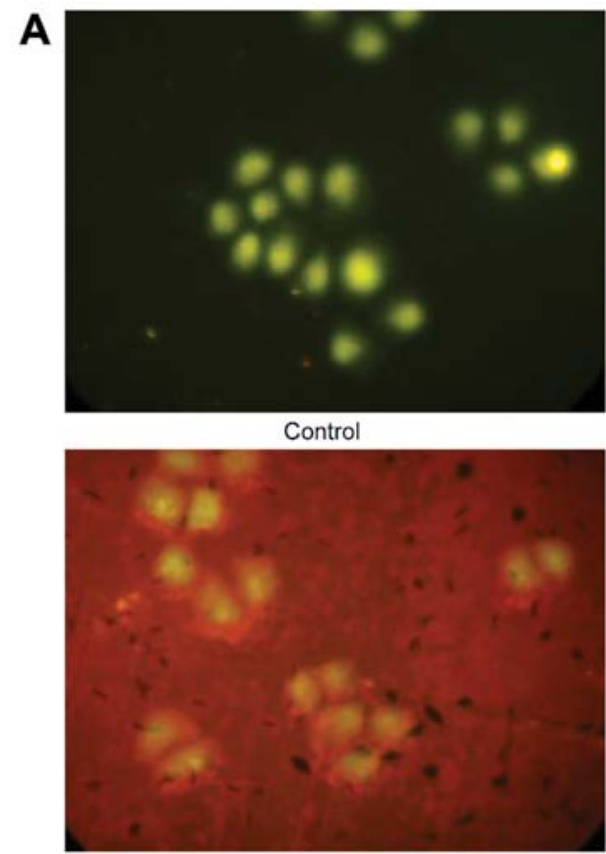

$1.0 \mu \mathrm{g} / \mathrm{ml} \mathrm{NC}$

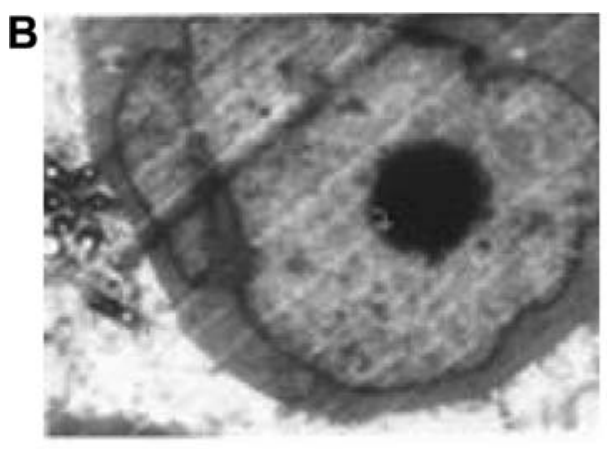

Control

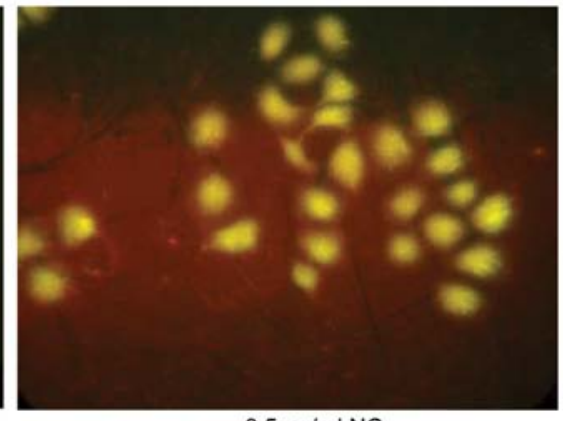

$0.5 \mu \mathrm{g} / \mathrm{ml} \mathrm{NC}$

Figure 3. NC-treated SMMC-7221 cells exhibit apoptotic morphology. (A) SMMC-7221 cells were treated with $0,0.5$ or $1.0 \mu \mathrm{g} / \mathrm{ml} \mathrm{NC}$ for $48 \mathrm{~h}$ and stained with $\mathrm{AO}$ and examined by fluorescent microscopy (x400 magnification). (B) Ultrastructural changes in SMMC-7721 morphology were examined by transmission electron microscopy following treatment with $\mathrm{NC}$. $\mathrm{AO}$, acridine orange; $\mathrm{NC}$, nitidine chloride.

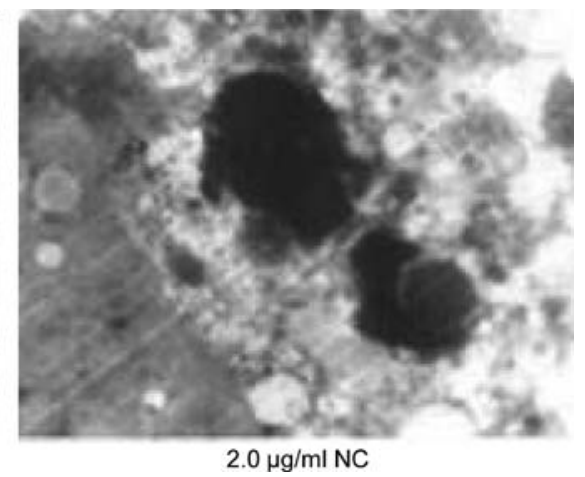

control and cells treated with 0.5 or $1.0 \mu \mathrm{g} / \mathrm{ml} \mathrm{NC}$ were stained with $\mathrm{AO}$ and visualized under a fluorescent microscope. Cells incubated with AO had green nuclei and yellow chromatin, whereas the cells treated with NC showed typical apoptotic changes, such as chromatin condensation and deformed and fragmented nuclei, particularly in the $1.0 \mu \mathrm{g} / \mathrm{ml} \mathrm{NC}$ treatment group (Fig. 3A). These results suggested that the cytotoxicity of NC involves the induction of apoptotic cell death.

To confirm the cell apoptosis induced by $\mathrm{NC}$, we used TEM to examine ultrastructural changes in SMMC-7721 cells after NC treatment. The nuclei and chromatin of control cells appeared normal (Fig. 3B). However, after 24-h treatment with $\mathrm{NC}(2.0 \mu \mathrm{g} / \mathrm{ml})$, chromatin margination, chromatin condensation, vacuolation in the cytoplasm and apoptotic body formation were observed (Fig. 3B). These results provided further evidence for the morphological induction of apoptosis as a consequence of $\mathrm{NC}$ treatment.

NC induces cell apoptosis as assessed by Annexin V-FITC/PI staining and caspase-3 activation. To confirm that NC induces apoptosis,SMMC-7721 cells were stained with Annexin V-FITC and PI, and subsequently analyzed by flow cytometry. In untreated cells, only $(2.00 \pm 0.06 \%)$ of SMMC-7721 cells were Annexin $\mathrm{V}^{+} / \mathrm{PI}^{-}$at $24 \mathrm{~h}$ of incubation. However, following
Cytomorphological effects of NC on SMMC-7721 cells. The mode of tumor cell killing by most anticancer agents is apoptotic cell death, and DNA fragmentation is a hallmark of this process (25). To further examine whether apoptosis occurs in cultured SMMC-7721 cells in response to NC treatment,

$\mathrm{NC}$ inhibits cell proliferation in a dose-dependent manner in SMMC-7721 cells by inducing $\mathrm{G}_{2} / \mathrm{M}$ arrest. 

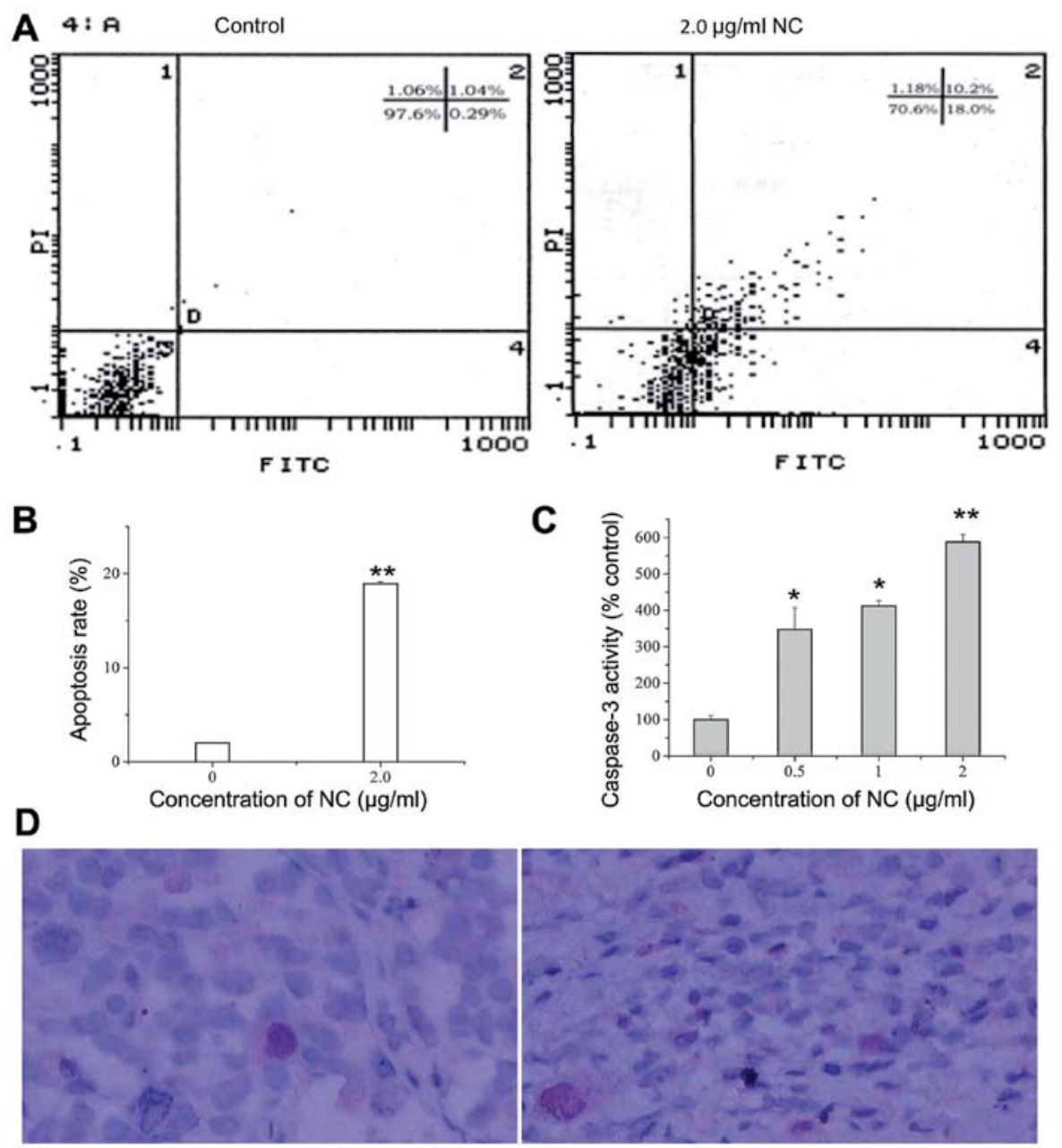

Figure 4. NC activates apoptosis in SMMC-7221 cells as assessed by Annexin V/PI staining and caspase-3 activation. (A) SMMC-7721 cell apoptosis was assessed by flow cytometry after Annexin V-FITC/PI staining of control cells or cells treated with $2.0 \mu \mathrm{g} / \mathrm{ml} \mathrm{NC}$ for $24 \mathrm{~h}$ as indicated. The results shown are representative of three independent experiments. (B) The means \pm SD of the percentage apoptosis as determined by Annexin V/PI staining in (A) was calculated in three independent experiments. (C) The activation of caspase-3 in SMMC-7721 cells following NC treatment is shown. Results are presented as means \pm SD of three independent experiments. (D) Transplanted SMMC-7721 cells from nude mice were assessed ex vivo by the TUNEL assay after $10 \mathrm{mg} / \mathrm{kg} / \mathrm{day} \mathrm{NC}$ treatment for 14 days (x200 magnification). NC, nitidine chloride.

exposure to $2.0 \mu \mathrm{g} / \mathrm{ml} \mathrm{NC}$, the level of apoptotic cells was increased to $(18.9 \pm 0.23 \%)$ (Fig. $4 \mathrm{~A}$ and B).

Caspase-3 activation is a critical event in apoptosis induction. To verify that cell death in SMMC-7221 cells is activated by NC through a caspase-3-dependent pathway, we measured caspase-3 activity in SMMC-7721 cells following NC treatment. Increased caspase-3 activation was observed at the NC doses tested, with the greatest increase at the highest $\mathrm{NC}$ doses (Fig. 4C).

To test whether apoptosis also occurs in vivo following the treatment of mice with $\mathrm{NC}$, we prepared tissue sections from the tumors of nude mice transplanted with SMMC-7721 cells. TUNEL assays revealed increased levels of apoptosis in the tumor tissue of mice that were treated with NC (Fig. 4D). Collectively, these results verify that NC-induced cell death occurs in vitro and in vivo by the activation of apoptosis.

Effects of NC on the expression of apoptosis-related proteins in SMMC-7721 cells. To investigate the molecular mechanism of NC-induced apoptosis in SMMC-7721 cells, the expression levels of several apoptosis-related proteins were examined. As assessed by ELISA, NC-induced a dose-dependent increase in the expression of the tumor suppressor p53 and the cyclin-dependent kinase inhibitor $\mathrm{p} 21$ after exposure to $\mathrm{NC}$ for $24 \mathrm{~h}$ (Fig. 5A). The increase in the two proteins was verified by qPCR (P<0.01; Fig. 5B).

The role of the $\mathrm{Bcl}-2$ family proteins, $\mathrm{Bcl}-2$ and Bax was also assessed. Immunohistochemical staining results showed that $\mathrm{NC}$ induced an increase in the pro-apoptotic Bax protein and a decrease in the apoptosis regulatory protein, Bcl-2 (Fig. 5C, Table IV). These results defined a pathway of apoptosis that involves the modulated expression of p53, p21, Bax and Bcl-2.

p53 modulates the effect of NC on SMMC-7721 cells. To investigate the role of p53 on the effect of NC on SMMC7721 cells, we transfected SMMC-7721 cells with shRNA against p53 and assessed growth inhibition by NC. The results showed that the effects of NC in inhibiting cell growth in p53 knockdown cells were reduced at 24 and $48 \mathrm{~h}$ following treatment (Fig. 6A). Furthermore, p53 knockdown cells had less bright $\mathrm{AO}$ staining, further suggesting protection from NC-induced cell death (Fig. 6B). To verify the effects of p53 
Table IV. Effects of $2 \mu \mathrm{g} / \mathrm{ml} \mathrm{NC}$ on the protein levels of Bax and Bcl-2 on SMMC-7721 cells after $24 \mathrm{~h}$ cultivation (mean $\pm \mathrm{SD}, \mathrm{n}=3$ ).

\begin{tabular}{llclcr}
\hline & \multicolumn{2}{c}{ Bax } & & \multicolumn{2}{c}{ Bcl-2 } \\
\cline { 2 - 3 } \cline { 5 - 6 } Groups & $\begin{array}{c}\text { No. of } \\
\text { positive cells }\end{array}$ & $\mathrm{A}_{\mathrm{OD}}$ & & $\begin{array}{c}\text { No. of } \\
\text { positive cells }\end{array}$ & $\mathrm{A}_{\mathrm{OD}}$ \\
\hline Control & $28.24 \pm 0.991$ & $194.29 \pm 4.251$ & & $49.78 \pm 2.611$ & $182.14 \pm 4.436$ \\
$\mathrm{NC}$ & $48.49 \pm 1.533^{\mathrm{a}}$ & $187.71 \pm 7.473$ & & $19.89 \pm 2.018^{\mathrm{a}}$ & $194.56 \pm 5.047$ \\
\hline
\end{tabular}

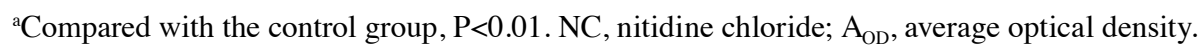
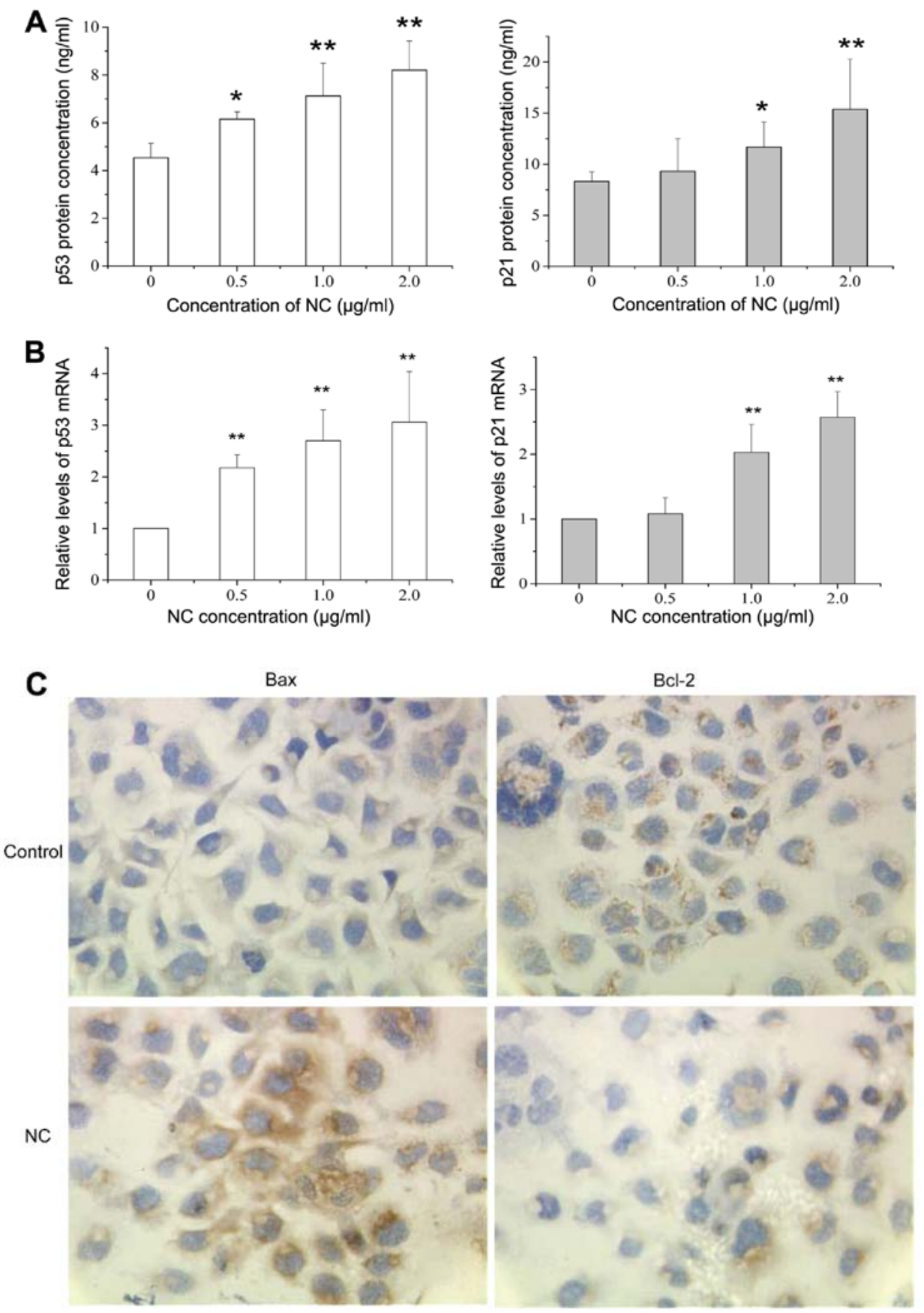

Figure 5. NC modulates the expression of apoptosis-related proteins in SMMC-7721 cells. (A) p53 and p21 protein expression was assessed by ELISA of SMMC-7221 cells after exposure to increasing doses of NC. (B) p53 and p21 mRNA expression was assessed by qPCR of SMMC-7221 cells after exposure to increasing doses of NC. (C) Immunohistochemical staining of Bax and Bcl-2 is shown for untreated SMMC-7721 cells (control) and cells treated with $2.0 \mu \mathrm{g} / \mathrm{ml} \mathrm{NC}$ for $24 \mathrm{~h}$ (x400 magnification). Results are representative of three independent experiments. ${ }^{*} \mathrm{P}<0.05 ;{ }^{* *} \mathrm{P}<0.01$ compared with control group (untreated). NC, nitidine chloride. 

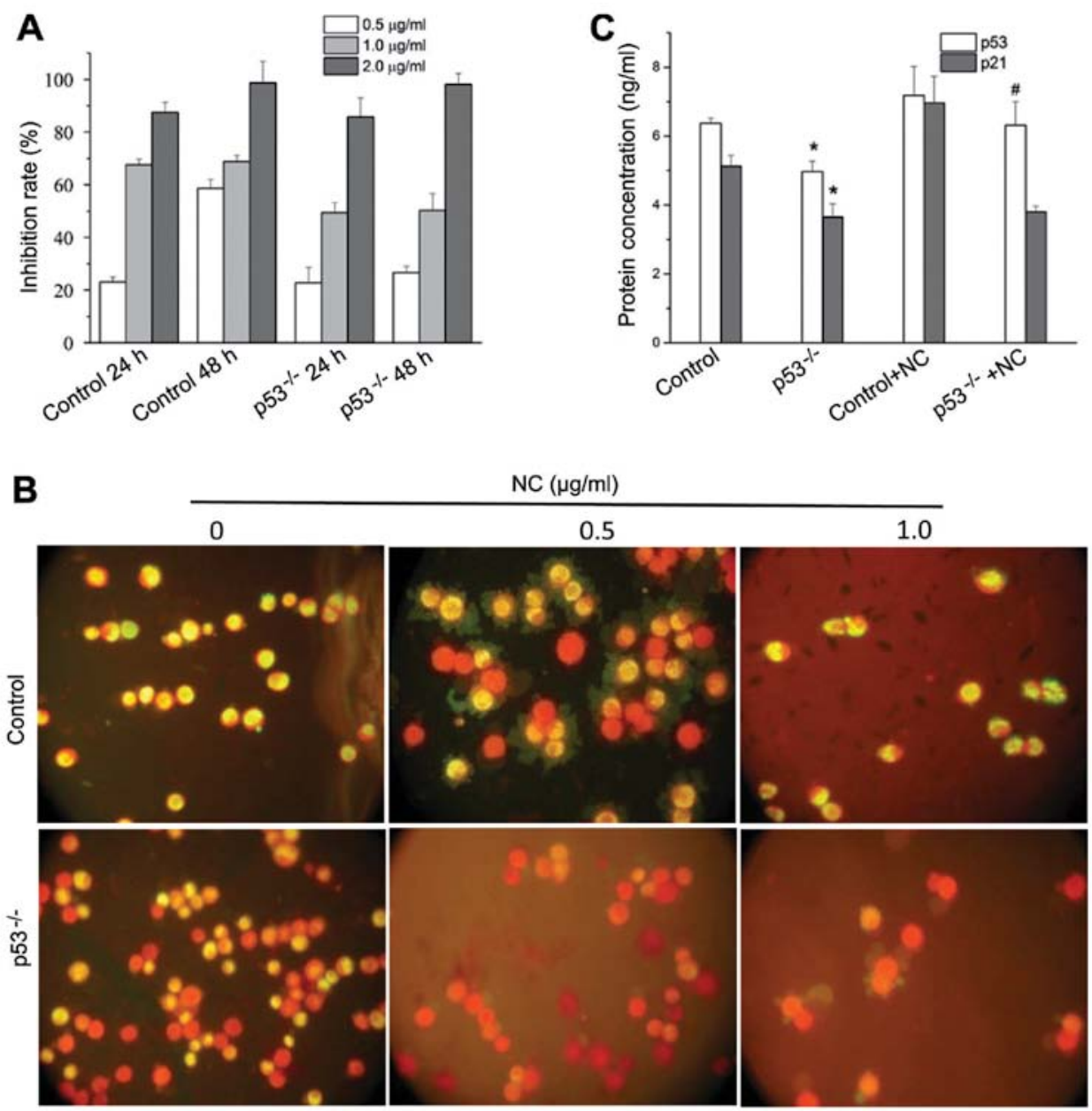

Figure 6. The role of 553 in mediating NC effects on SMMC-7721 cells and p21 expression. (A) Inhibition by NC of cell growth was measured by MTT assay for SMMC-7721 cells transfected with p53 shRNA (p53 $3^{-/}$) or control shRNA (Control) and treated for $24 \mathrm{~h}$ with $0.5,1.0 \mathrm{or} 2.0 \mu \mathrm{g} / \mathrm{ml} \mathrm{NC}$. (B) The morphological changes in transfected cells were examined by AO staining and fluorescent microscopy for SMMC-7221 cells transfected with control shRNA for $24 \mathrm{~h}$, or transfected with p53 shRNA for $24 \mathrm{~h}$. Following transfection, the cells were exposed to $0,0.5$ or $1.0 \mu \mathrm{g} / \mathrm{ml}$ of NC for $24 \mathrm{~h}$ as indicated (x 200 magnification). (C) Proteins expression in transfected cells was examined by ELISA following transfection with control shRNA or p53 shRNA and with or without NC treatment as indicated. Values are presented as means \pm SD of at least three independent experiments * $\mathrm{P}<0.05$ compared with untreated cells. $\mathrm{NC}$, nitidine chloride; $\mathrm{AO}$, acridine orange.

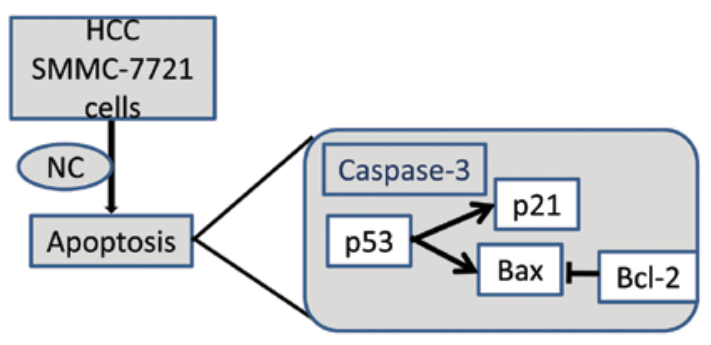

Figure 7. Model summarizing the apoptosis in HCC induced by plant-derived chemopreventive agent NC. NC induces the apoptosis of HCC SMMC-7721 cells through a pathway involving $\mathrm{p} 53, \mathrm{p} 21$, Bax and Bcl-2. NC, nitidine chloride.

knockdown on p53 expression levels, we assessed these levels using ELISA. The results confirmed that p53 was increased significantly after $\mathrm{NC}$ treatment, but that this increase was ablated by knockdown (Fig. 6C). Notably, p21 expression also showed a similar pattern of increase by $\mathrm{NC}$ and reduction following p53 knockdown (Fig. 6D). These results suggested that p53 is important in NC-induced apoptosis of SMMC-7721 and that $\mathrm{p} 21$ expression is concomitant, and may be regulated by 53 expression.

\section{Discussion}

Despite the current advances in anticancer therapies, the clinical prognosis of HCC remains poor. For this reason, the identification of novel effective drugs with low systemic toxicity is a primary focus of oncology research. NC has been shown to exert growth inhibitory effects on several neoplasms (26). Findings of recent studies have shown that $\mathrm{NC}$ can inhibit HCC cell proliferation in vitro (27). However, its effects in vivo and its mechanism in inhibiting HCC cell growth remained unclear. In the present study, we confirmed that $\mathrm{NC}$ reduces proliferation of the SMMC-7721 liver cancer cell line in a dose- and time-dependent manner. We also established a human HCC SMMC-7721 xenograft model in nude mice to verify the antitumor effects of NC and showed that NC significantly inhibits the growth of transplanted SMMC-7721 HCC tumors. These results confirm the effects 
on NC in inhibiting SMMC-7221 cell growth in vitro and in vivo and suggest that $\mathrm{NC}$ serves as a candidate therapeutic agent for HCC.

Cell cycle arrest has been shown to lead to cell growth inhibition and can serve as a marker for chemopreventive or antitumor activity of chemicals or drugs (24). We have demonstrated that $\mathrm{NC}$ promotes $\mathrm{G}_{2} / \mathrm{M}$ phase cell cycle arrest, which was statistically validated for higher doses of NC. These results suggest that the growth inhibition by $\mathrm{NC}$ may be mediated in part by cell cycle arrest.

Apoptosis is a form of physiological programmed cell death and a key pathway for regulating homeostasis and morphogenesis of mammalian cells that is connected with several diseases, including cancer (28). As a significant mode of cell death after cytotoxic drug treatment in a variety of cancer types, apoptosis induction is a recognized strategy for anticancer drugs (29). Current efforts regarding anticancer drug development have focused on directing tumor cells to undergo apoptosis (30), and substantial evidence indicates that alteration in the molecular pathways that control the cell cycle and apoptosis may change the sensitivity and resistance to anticancer agents (23). Using AO staining, we demonstrated that cells treated with NC exhibited an apoptotic morphology, including increased nuclear fluorescence, indicative of DNA fragmentation. Internucleosomal DNA fragmentation is an early biochemical characteristic representing a point of no return in the pathway to apoptosis (31). These observations provide evidence that an apoptotic pathway occurs following $\mathrm{NC}$ treatment. To confirm the cell apoptosis induced by NC, we examined ultrastructural changes in SMMC-7721 cells by TEM. Chromatin margination, chromatin condensation, vacuolation in the cytoplasm and apoptotic body formation was observed following $\mathrm{NC}$ treatment, providing further evidence for the induction of apoptosis as a consequence of $\mathrm{NC}$ treatment. The ability of $\mathrm{NC}$ to induce apoptosis was verified by Annexin V/PI staining and caspase-3 activation assays. Therefore, a combination of results suggest apoptosis as a mechanism for $\mathrm{NC}$ function.

To further understand the mechanism of $\mathrm{NC}$ in inducing growth inhibition, cell cycle arrest and apoptosis, we examined common regulators of these processes. The p53 tumor suppressor gene plays a crucial role in protecting organisms from developing cancer (32) and also acts as a cellular stress sensor (33). In response to a number of forms of stress, including hyperproliferation, DNA damage and hypoxia, p53 elevation signals $\mathrm{G}_{1}$ phase arrest and apoptosis (32). Notably, in the present study, we found that NC induced p53 in SMMC7721 cells as assessed by ELISA and qPCR. This finding demonstrates that $\mathrm{NC}$ may induce apoptosis by upregulating p53. p53 encodes a transcription factor, which contributes to the transcriptional activation of a large number of targets, including p21 and the pro-apoptotic proteins Bax, PUMA and NOXA (34). Thus, it is likely that p53 acts upstream of other pro-apoptotic proteins to modulate their functions in cytoplasm.

The results also show that NC induced the cyclin-depen-

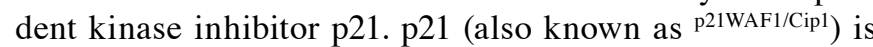
induced by p53-dependent- and -independent mechanisms following stress, and induction of p21 causes a cell cycle arrest, which often protect cells from apoptosis $(35,36)$. Thus, the activation of p21 may be induced as a response to the increase in $\mathrm{p} 53$ by NC.

p53 can also upregulate Bax in response to a variety of p53-dependent apoptosis triggers (37). Our results show that Bax was significantly upregulated while $\mathrm{Bcl}-2$ was downregulated following exposure to $\mathrm{NC}$ for $24 \mathrm{~h}$. Although the two proteins are related structurally, Bax is pro-apoptotic, while Bcl-2 indirectly inhibits apoptosis by inhibiting the opening of permeability transition channels on mitochondria and thereby lowering the mitochondrial potential $(38,39)$, blocks the release of cytochrome $c$ and promotes activation of caspase-3. Therefore, the upregulation of Bax and downregulation of Bcl-2 nay contribute to the NC-dependent induction of HCC cell death.

Mutations of the $p 53$ gene are the most frequent genetic change in human cancers. It is estimated that $~ 50 \%$ of all human malignancies contain mutations in this gene $(40,41)$. Furthermore, p53 and p21 are necessary to maintain a $\mathrm{G}_{2} / \mathrm{M}$ arrest and apoptosis following DNA damage (42). Thus, it is likely p53 induction plays a major role in triggering the pathway of response to NC elucidated in the present study (Fig. 7), thereby demonstrating that its downstream targets in the induction of cytotoxicity in $\mathrm{HCC}$ are important in understanding the mechanisms involved in $\mathrm{NC}$ function. However, the demonstration of p53-mediated apoptosis in the present study provides a foundation for understanding the anticarcinogenic effect of NC on HCC and suggests its potential as a candidate therapeutic drug for HCC.

\section{Acknowledgements}

This study was supported by the Natural Science Foundation of China, nos. 81260657, 30850010, 30672363, 30870903 and 30950028 .

\section{References}

1. Al-Rawashdeh FY, Scriven P, Cameron IC, Vergani PV and Wyld L: Unfolded protein response activation contributes to chemoresistance in hepatocellular carcinoma. Eur J Gastroenterol Hepatol 22: 1099-1105, 2010.

2. Parkin DM, Bray F, Ferlay J and Pisani P: Global cancer statistics, 2002. CA Cancer J Clin 55: 74-108, 2005.

3. Roberts LR and Gores GJ: Emerging drugs for hepatocellular carcinoma. Expert Opin Emerg Drugs 11: 469-487, 2006.

4. Man S, Gao W, Wei C and Liu C: Anticancer drugs from traditional toxic Chinese medicines. Phytother Res 26: 1449-1465, 2012.

5. Editorial Board of Chinese Materia Medica, State Administration of Traditional Chinese Medicine of China: Chinese Materia Medica. Shanghai Science and Technology Press, Shanghai, pp3821, 1999.

6. Yang CL: Poison Materia Medica. Chinese Medicine Press, Beijing, pp431, 1993.

7. Huang ZX and Li ZH: Studies on the antitumor constituents of Zanthoxylum nitidum (Roxb) DC. Acta Chimica Sinica 38: 535-542, 1980.

8. Liu HG, Huang QJ and Lai MX: Review of Zanthoxylum nitidum. Lishizhen Med Mater Med 18: 222-223, 2007.

9. Sethi VS: Inhibition of mammalian and oncornavirus nucleic acid polymerase activities by alkoxybenzophenanthridine alkaloids. Cancer Res 36: 2390-2395, 1976.

10. Cushman M, Mohan P and Smith EC: Synthesis and biological activity of structural analogues of the anticancer benzophenanthridine alkaloid nitidine chloride. J Med Chem 27: 544-547, 1984

11. Iwasaki H, Okabe T, Takara K, Toda T, Shimatani M and Oku H: Tumor-selective cytotoxicity of benzo[c]phenanthridine derivatives from Toddalia asiatica Lam. Cancer Chemother Pharmacol 65: 719-726, 2010. 
12. Fan YJ, Zhou J and Li M: Effect of nitidine chloride on the life cycle of Ehrlich ascites carcinoma cells in mice. Zhongguo Yao Li Xue Bao 2: 46-49, 1981 (In Chinese).

13. Pan X, Han H, Wang L, Yang L, Li R, Li Z, Liu J, Zhao Q, Qian M, Liu M and Du B: Nitidine chloride inhibits breast cancer cells migration and invasion by suppressing c-Src/FAK associated signaling pathway. Cancer Lett 313: 181-191, 2011.

14. Xu Q, Li ZX and Ye ZM: Nitidine chloride-induced apoptosis of human osteosarcoma cells and its mechanism. Nan Fang Yi Ke Da Xue Xue Bao 31: 361-364, 2011 (In Chinese).

15. Chen J, Wang J, Lin L, He L, Wu Y, Zhang L, Yi Z, Chen Y, Pang $X$ and Liu M: Inhibition of STAT3 signaling pathway by nitidine chloride suppressed the angiogenesis and growth of human gastric cancer. Mol Cancer Ther 11: 277-287, 2012.

16. Fang Z, Tang Y, Jiao W, Xing Z, Guo Z, Wang W, Shi B, Xu Z and Liu Z: Nitidine chloride inhibits renal cancer cell metastasis via suppressing AKT signaling pathway. Food Chem Toxicol 60: 246-251, 2013.

17. Iwasaki H, Okabe T, Takara K, Yoshida Y, Hanashiro K and Oku H: Down-regulation of lipids transporter ABCA1 increases the cytotoxicity of nitidine. Cancer Chemother Pharmacol 66 : 953-959, 2010.

18. Liu HG, Qin SH, Wang BL and Yang B: Effect of nitidine chloride induced apoptosis in two nasopharyngeal carcinoma cell lines in vitro. West China J Pharm Sci 22: 514-516, 2007.

19. Liu HG, Wang BL, Qin SH and Yang B: Studies on $\mathrm{G}_{2} / \mathbf{M}$ phase arrest and apoptosis of human carcinoma of mouth floor KB cell in vitro induced by nitidine chloride. Lishizhen Med Mater Med 18: 2104-2106, 2007.

20. Wei M, Liu HG, Liu LM and Li DN: In vitro nephrotoxicity of nitidine chloride in human liver L-O2 and kidney 293 cells. Chin J New Drugs 19: 56-59, 63, 2010.

21. Aamdal S, Fodstad O, Nesland JM and Pihl A: Characteristics of human tumour xenografts transplanted under the renal capsule of immunocompetent mice. Br J Cancer 51: 347-356, 1985.

22. Soto-Cerrato V, Viñals F, Lambert JR and Pérez-Tomás R: The anticancer agent prodigiosin induces $\mathrm{p} 21^{\mathrm{WAF} / \mathrm{CIP} 1}$ expression via transforming growth factor-beta receptor pathway. Biochem Pharmacol 74: 1340-1349, 2007.

23. O'Connor P: Mammalian G1 and G2 phase checkpoints. Cancer Surv 29: 151-182, 1997.

24. Chang J: Scientific evaluation of traditional Chinese medicine under DSHEA: a conundrum. Dietary Supplement Health and Education Act. J Altern Complement Med 5: 181-189, 1999.

25. Kerr J, Wyllie A and Currie A: Apoptosis: a basic biological phenomenon with wide-ranging implications in tissue kinetics. Br J Cancer 26: 239-257, 1972.

26. Ludwig HC, Akhavan-Shigari R, Rausch S, Schallock K and Quentin C, Bockermann V and Kolenda H: Expression of focal adhesion kinase (p125 FAK) and proline-rich tyrosine kinase 2 (PYK2/CAKb) in cerebral metastases, correlation with VEGF-R-, ecNOS III-labelling and morphometric data. Anticancer Res 20: 1419-1424, 2000.
27. Liao J, Xu T, Zheng JX, Lin JM, Cai QY, Yu DB and Peng J: Nitidine chloride inhibits hepatocellular carcinoma cell growth in vivo through the suppression of the JAK1/STAT3 signaling pathway. Int J Mol Med 32: 79-84, 2013.

28. Goldsworthy TL, Conolly RB and Fransson-Steen R: Apoptosis and cancer risk assessment. Mutat Res 365: 71-90, 1996.

29. Powell C, Fung P, Jackson J, Dall'Era J, Lewkowicz D, Cohen I and Smith-McCune K: Aqueous extract of herba Scutellaria barbatae, a Chinese herb used for ovarian cancer, induces apoptosis of ovarian cancer cell lines. Gynecol Oncol 91: 332-340, 2003.

30. Yuan CH, Filippova M and Duerksen-Hughes P: Modulation of apoptotic pathways by human papillomaviruses (HPV): mechanisms and implications for therapy. Viruses 4: 3831-3850, 2012.

31. Allen RT, Hunter WJ III and Agrawal DK: Morphological and biochemical characterization and analysis of apoptosis. J Pharmacol Toxicol Methods 37: 215-228, 1997.

32. Levine AJ: p53, the cellular gatekeeper for growth and division. Cell 88: 323-331, 1997.

33. Giaccia AJ and Kastan MB: The complexity of p53 modulation: emerging patterns from divergent signals. Genes Dev 12: 2973-2983, 1998.

34. Mirzayans R, Andrais B, Scott A and Murray D: New insights into p53 signaling and cancer cell response to DNA damage: implications for cancer therapy. J Biomed Biotechnol 2012: 170325,2012

35. Abbas T and Dutta A: p21 in cancer: intricate networks and multiple activities. Nat Rev Cancer 9: 400-414, 2009.

36. Gartel AL and Tyner AL: The role of the cyclin-dependent kinase inhibitor p21 in apoptosis. Mol Cancer Ther 1: 639-649, 2002.

37. McGill G and Fisher DE: Apoptosis in tumorigenesis and cancer theraphy. Front Biosci 2: d353-d379, 1997.

38. Kim CN, Wang X, Huang Y, Ibrado AM, Liu L, Fang G and Bhalla K: Overexpression of Bcl- $\mathrm{X}_{\mathrm{L}}$ inhibits Ara-C-induced mitochondrial loss of cytochrome $c$ and other perturbations that activate the molecular cascade of apoptosis. Cancer Res 57: 3115-3120, 1997.

39. Rossé T, Olivier R, Monney L, Rager M, Conus S, Fellay I, Jansen B and Borner C: Bcl-2 prolongs cell survival after Bax-induced release of cytochrome $c$. Nature 391: 496-499, 1998.

40. Olivier M, Hollstein M and Hainaut P: TP53 mutations in human cancers: origins, consequences, and clinical use. Cold Spring Harb Perspect Biol 2: a001008, 2010.

41. Osborne C, Wilson P and Tripathy D: Oncogenes and tumor suppressor genes in breast cancer: potential diagnostic and therapeutic applications. Oncologist 9: 361-377, 2004.

42. Winters ZE: P53 pathways involving G2 checkpoint regulators and the role of their subcellular localisation. JR Coll Surg Edinb 47: 591-598, 2002. 